\title{
WILL AN UNDERWATER ROBOT EVER REPLACE THE DIVER? A RATHER POOR PROGRESS OR A GREAT SUCCESS?
}

\author{
Adam Olejnik $^{1)}$, Piotr Siermontowski ${ }^{2)}$ \\ 1) Polish Naval Academy, Department of Underwater Work Technology \\ ${ }^{2)}$ Military Institute of Medicine, Department Maritime and Hyperbaric Medicine, Gdynia, Poland
}

\section{ABSTRACT}

The article deals with the subject matter related to the development of underwater works technologies. Nearly 15 years ago one of the authors of this study published a material in the monthly magazine of "Podwodny Swiat" (The Underwater World) entitled "The Future of Underwater Technologies - the diver or the robot?" where he noted that the time of great changes in technologies aimed at researching the depths and conducting works under water has arrived. This new era mainly consists in the fact that on an increasing number of occasions the diver is replaced by an underwater robot. The presented material constitutes an attempt to provide an answer to the question whether the then posed thesis is still valid. In the article the authors discuss issues concerned with the development of techniques and technologies applied in the conquest of depths that leads them to the conclusion that the previously observed tendency of a double-tracked development of underwater technologies is gaining in strength, which causes that the works and exploration of bodies of water at great depths will be possible only with the use of unmanned techniques.

Key words: underwater works technology, marine engineering.

\section{ARTICLE INFO}

PolHypRes 2016 Vol. 54 Issue 1 pp. 7-18

ISSN: $1734-7009$ eISSN: 2084-0535

DOI: 10.1515/phr-2016-0001

Pages: 13 , figures: 11 , tables: 0

page www of the periodical: www.phr.net.pl

Publisher

Polish Hyperbaric Medicine and Technology Society
Review article

Delivery date: 29.10 .2015 r.

Date of approval for print: 22.11.2015r. 


\section{INTRODUCTION}

The last 20 years of development of underwater works technologies have been an ongoing festival of remotely controlled abyssal vehicles. The turn of the 1980 s and 1990s, which is generally accepted to be the time of its commencement, was a period of the thus far unknown expansion in the development of such devices mainly exhibited in the significant increase in the number of operated tools and an extended scope of their application [1]. When establishing SeaBotix Inc. in 1999, Don Rodocker assumed that the vehicles should be available, economic and usable by numerous potential users. It is, amongst other things, thanks to the activity of such companies that such devices are used practically everywhere, resulting in the enhanced effectiveness of the implemented works.

In particular, with their use, it is also possible to elevate safety standards in the working environments in which they are deployed. Of course, with a brief look at the reported applications of these vehicles from around the world, we can see that today, they are mainly deployed on observational tasks. . Nearly $60 \%$ of them are vehicles whose tasks consist in transmitting visual information concerning the situation in an underwater station. However, according to more recent analyses of the research projects implemented in this area, the use of these vehicles is now changing.

The material published nearly 15 years ago puts forward a thesis that underwater works technologies will be developing towards the increasing use of unmanned techniques, and that in the future, the presence of man at great depths will only be possible virtually [2]. Moreover, it was indicated that multiple tasks in the sea will be taken over by unmanned superficial vehicles, cooperating with other unmanned equipment, and that autonomous underwater vehicles will find a broad application in the exploration of large marine bodies of water. The question is whether the then made prediction is still valid, or completely outdated? The presented material is an attempt to answer the above question.

\section{A RATHER POOR PROGRESS OR A GREAT}

\section{SUCCESS?}

Human race has been engaged in performing works under water with the use of various technologies for several thousand years. Certain documented traces of human work in the depths of water date back to the times of reign of the Chinese emperor YU, i.e. over 2000 years ACN (fig. 1.1), (Fig.1.2) [3,4,5].

This means that the process of development of underwater works technologies is a long one. However, if the success in this area were to be measured by the maximum depth reached by a man unequipped in a solid diving suit, a thesis could be made that such a success was rather poor. For example, it has been only 70 years since the first flight performed by the Wright brothers (17 December 1903), or setting foot on the Moon by the first man (21 July 1969)!

Only a little over a half of a century ago, we were able to transform from an earth species to a species reaching for other astronomical objects.

The situation slightly differs with view to underwater works technology. As S. Halbron put it in his book entitled "5000 metres under water" [6]: "[...] The history of divers is long and rich: rich in human tragedies for whom their personal participation ended with blindness, pulmonary adenomatosis or death by shark attack. [....] Thus, the history of diving is not complete but rather limited - limited by depth".

The maximum depth reached by a diver is approximately 600 metres [7], whereas the highest pressure that a man was subjected to in a hyperbaric facility corresponded to the depth of $704 \mathrm{~m}$. The said exposure was performed in 1974 in the research centre of the Comex company in France. It was participated by 4 divers, with only one of them reaching the greatest "depth" and the remaining ones not exceeding the limit of $700 \mathrm{~m}$.

This means that despite several thousand years of development of underwater technologies we have reached only $6 \%$ of the maximum available scope of oceanic depth registered on Earth. Following this kind of reasoning, and combining it with the progress made in aviation, we may become truly concerned and assume that the success in the technology of underwater works is rather insignificant.

But is this really so? Look at the number of solutions provided to difficult issues, the original and interesting constructions allowing conquest of the depths. How much greater is the scale of difficulty here! Even in comparison with flights into the space. It is a fact that a diver submerged to the depth of only 10 metres is subject to pressure differences similar to those experienced by an astronaut during a flight to the Earth's orbit.

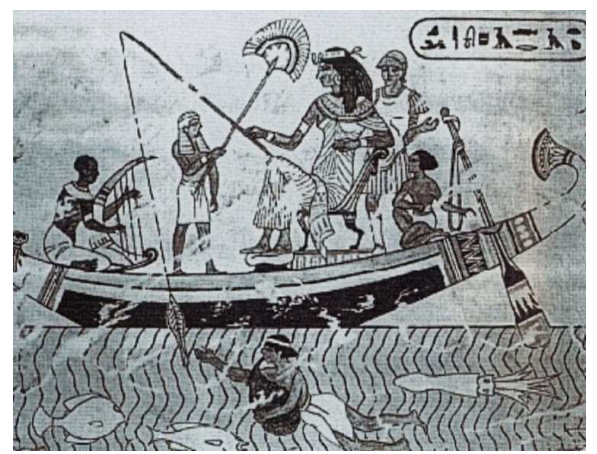

Fig. 1.1. Ancient Egypt, on Cleopatra's request divers attach fish to Mark Antony's fishing rod [5] 


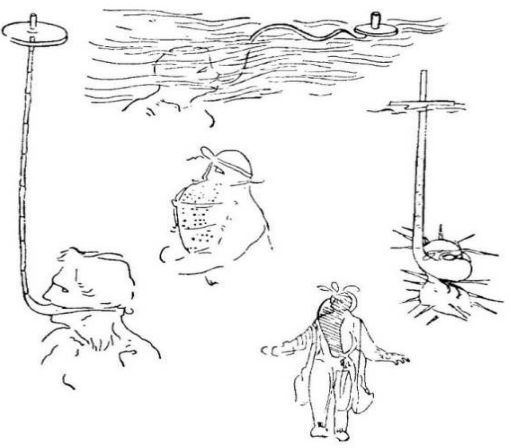

Fig. 1.2. Devices allowing breathing under water proposed by Leonardo da Vinci in Codex Atlanticus [3].

Irrespective of the type of underwater works performed by divers, two primary problems always occurred in their implementation. The first consisted in reaching an underwater station. The second, more complex, involved the diver's return to normobaric conditions. This stems from the fact that the first problems in underwater works technology appear already at the depth of 50 centimetres from which point their number only increases $[8,9]$.

Already at such a small depth it is difficult for a man to take a breath with the use of a breathing tube from the surface and for this reason the solutions presented in Fig. 1.2, despite their origin, should be treated as a one of the voices raised in the discussion, without the possibility of their practical application.

Because the pressure exerted by hydrostatic pressure on the chest at the depth of $50 \mathrm{~cm}$ makes it impossible to draw a breath from the surface, i.e. at the atmospheric pressure. In order for a man to safely breathe under water it is necessary to be equipped in devices supplying him with a breathing mix under pressure corresponding to the current diving depth. For a number of years of the technical progress in this area, numerous constructions have been invented and built (Fig. 1.3) [10].

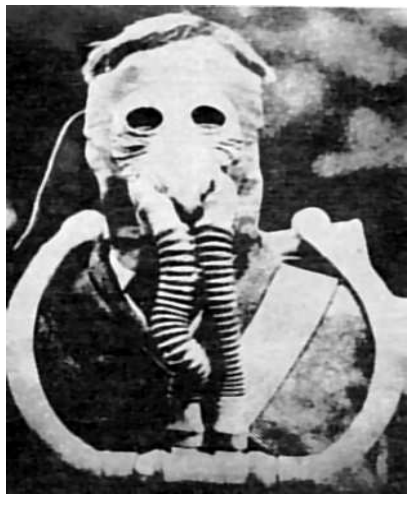

Fig. 1.3. The first oxygen apparatus by Henry Fluess, 1878 [10].

These activities were directed mainly at enabling breathing under water and maximum elongation of the equipment's protective operational time. Hence, open-circuit, semi-closed and closed-circuit diving apparatuses were constructed. Each of them is characterised by one primary function of the objective, consisting in the supply of the breathing mix, at a pressure corresponding to the hydrostatic pressure of the operating diving depth, with a shorter or longer protective operational time depending on the applied technical solution and needs.

Unfortunately, along with an increase in the diving depth our natural breathing mix becomes more and more dangerous for human organism. Breathing with compressed air at depths exceeding 30 metres, and in more sensitive individuals at lesser depths, can present the first symptoms of nitrogen narcosis. The scale of symptoms depends on individual sensitivity and resembles intoxication with alcohol.

Upon exceeding a depth of 55 metres, the abilities and functioning of a diver are no longer to be trusted, whereas at the depths greater than 80-90 metres the diver faces the risk of losing consciousness. Due to these facts, it was assumed that for safety reasons compressed air should only be used in the performance of underwater works at medium depths [11]. A way to increase the depth of works and enhance diving safety was sought in the application of breathing mixes other than air.

This set the background for the preparation of technologies of underwater diving works using artificial gas mixes: nitrogen-oxygen with an increased oxygen content (nitrox), helium-oxygen-nitrogen (trimix), oxygen-hydrogen (hydrox), oxygen-helium-hydrogen (hydreliox), and, currently not used in practice, oxygenneon mixes (neox) [12].

During experiments implemented in England in the 1970s it was found that helium does not induce narcotic symptoms, however at the depth exceeding 150 metres leads to the so-called HPNS - high pressure nervous syndrome. According to some researchers the said syndrome is a consequence of the effect of hydrostatic pressure and the compression speed [7]. There are multiple hypotheses concerning the reasons for HPNS, commonly it is believed that a very slow compression of $0.1-0.2 \mathrm{~m} / \mathrm{min}$ at large depths, should limit the occurrence of this phenomenon [13]. 
Another highly innovative and quite an unconventional approach to this issue consisted in the experiments of a Dutch physiologist, Johannes Kylstra, conducted in the 1960s [13]. In 1963, at a laboratory of the university in Leiden dr Kylstra induced oxygen absorption from water in mice and dogs that breathed with oxygen dissolve in water (Fig. 1.4).

The content and solubility of oxygen in water was increased by raising the pressure in the container to eight atmospheres, whereas the water in which the animals were placed was a saline solution with one third the salinity of sea water [14]. Shortly before leaving the water, the animals had their lungs dried out, thus enabling them to return to physiological breathing. Unfortunately, the experiment was only partly successful.
The lungs of mice were too small and could not be dried in time, hence after their removal from water all died. However, in the case of dogs, oxygen-enriched sea water proved to be suitable for respiration. Nonetheless, after the initial euphoria and promising results this technology was not accepted, despite its spectacular presentation in James Cameron's 1989 film ("The Abyss").

What appeared to be problematic was the period of stay in water during which the animals breathed with oxygen dissolved in it. The oxygen absorption was quite good, however there were problems connected with carbon dioxide removal [13]. The above issues are related with immersion and stay at the working depth. A return from this depth is even more complicated.
Fig. 1.4. The experiment of Dr. Kylstra, Leiden 1963 [13]

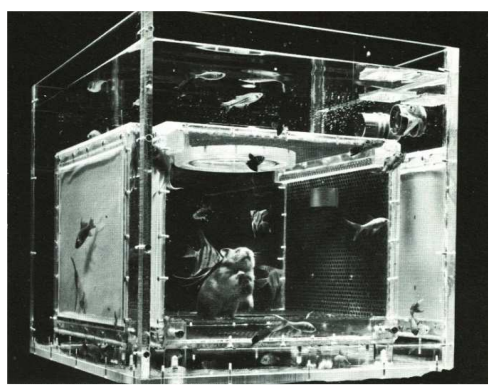

At the increased pressures associated with diving, nitrogen, or an alternative inert gas of the breathing mix, dissolves in the blood and is distributed to all the tissues in the body. The quantity of gas that can thus be transferred from the breathing mix into the organism during a stay at the working depth is immediately related to its partial pressure. Inert gas (e.g. nitrogen) is not consumed by the human organism, which means that the gas is collected in a diver's organism and needs to be removed during the process of ascent, called desaturation or, more commonly, decompression.

The idea of this process is that the inert gas that has been collected in the diver's organism during his/her immersion is safely removed via the same path, i.e. through the respiratory system. If this is not accomplished, gas bubbles are formed in various locations of the organism, thus inducing respective clinical symptoms.

For instance, an occurrence of bubbles in the synovial fluid or periosteum or perimysium will induce symptoms in the joint-muscle area. An occurrence of bubbles in the blood will lead to gas emboli, whereas their appearance in the adipose tissue will result, for instance, in dermal symptoms. Scientific awareness of these facts appeared as late as in 1878 when Paul Bert published his work entitled "La pression barométrique", where he proved, among other things, that nitrogen will collect in the blood if the body is subject to pressure [15]. The solution to this problem came along with the year 1905 when John Scott Haldan prepared the first decompression tables allowing divers to perform safe ascents to the surface [7].

During the ascent, divers ascended at a specified speed and stopped for a particular time at the so-called decompression stops, in order to remove the excess inert gas from within their organism which had accumulated during the process of diving, . The primary problem is the fact that the ratio of time needed for decompression to the time spent under maximum pressure along with an increase in the diving depth grows in accordance with the exponential curve (Fig. 1.5 \& 1.6).

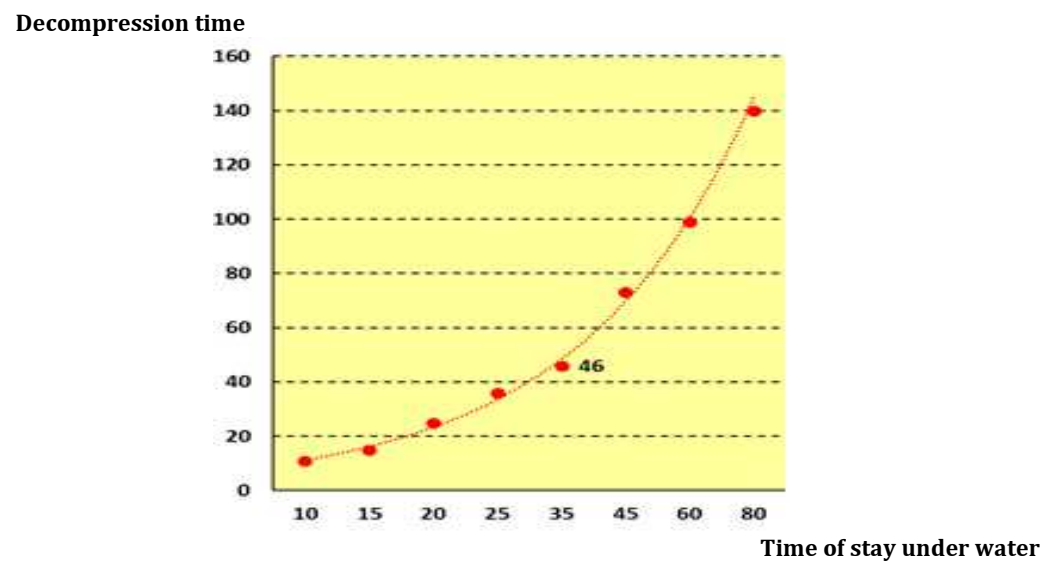

Fig. 1.5. Decompression time (vertical axis) in the function of stay time (horizontal axis) under maximum pressure for a dive performed at the depth of 42 metres with the use of air as the breathing mix (Naval Table). 
Decompression time

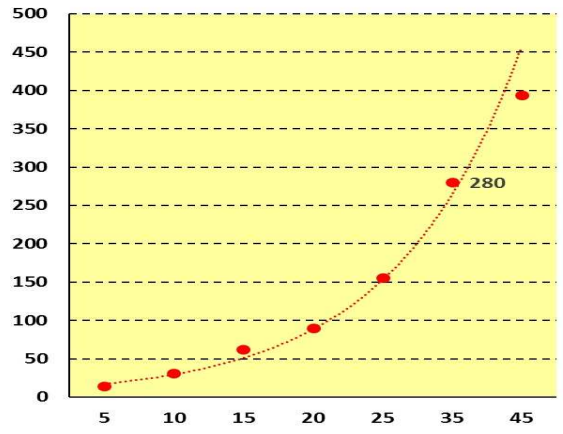

Time of stay under water

Fig. 1.6. Decompression time (vertical axis) in the function of stay time (horizontal axis) under maximum pressure for a dive performed at the depth of 80 metres with the use of air as the breathing mix (Naval Table) (the same stay time under maximum pressure as for the depth of 42 metres)(Fig. 1.5).

As visible in the above figures, a double increase in the operational depth results in increasing the time required for decompression by six times with the same stay time under maximum pressure, i.e. at the working depth. It is for these reasons that the technologies of longterm underwater works have been developed.

During their implementation, before diving commencement, divers are subject to compression corresponding to the depth of work inside a hyperbaric chamber. In its course the air atmosphere is replaced with a different, artificial breathing mix. Divers stay in the chamber until their organisms are fully saturated with inert gases. From that moment the time needed to perform decompression depends on the time of stay under maximum pressure. In these conditions divers remain in the decompression chamber and are delivered to the working station from the surface continuously kept under the pressure corresponding to the diving depth in a hermetic diving bell.

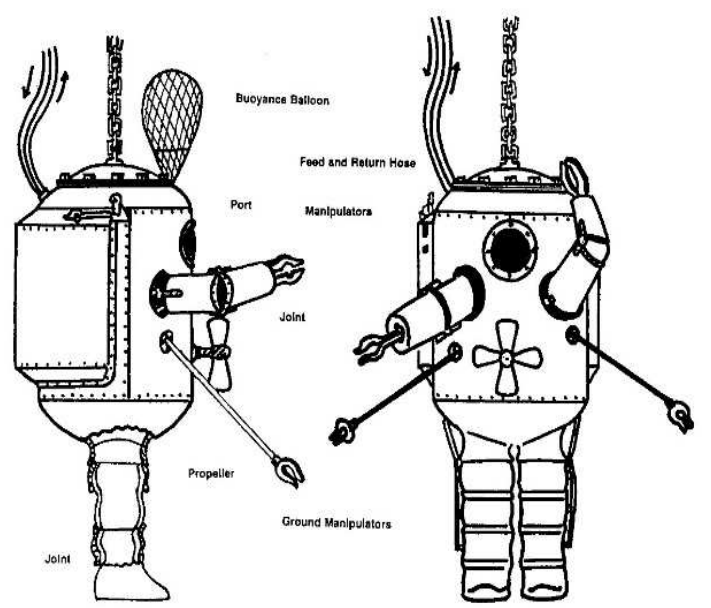

PHILLIPS DIVING ARMOUR

Fig. 1.7. Armoured suit by J. Philips (1856) [16].
The decompression procedure is initiated only upon the completion of all planned works at the bottom, which in this case lasts several days. Pursuant to the effective regulations the maximum time of such an exposure cannot exceed 672 hours along with decompression (JL no. 199 of 2003, it. 1936). This is the only technology of underwater works which ensures effective work of humans at large depths and for these reasons it is the one most commonly used by submarine extractive industries.

Unfortunately, it is hugely expensive and the psychophysical requirements set for the employees are grossly inflated. However, the performance of the saturated dives, causes numerous health effects and complications that are projected on to the current health status of the divers, and has a significant impact on the psychophysical conditions later in life.

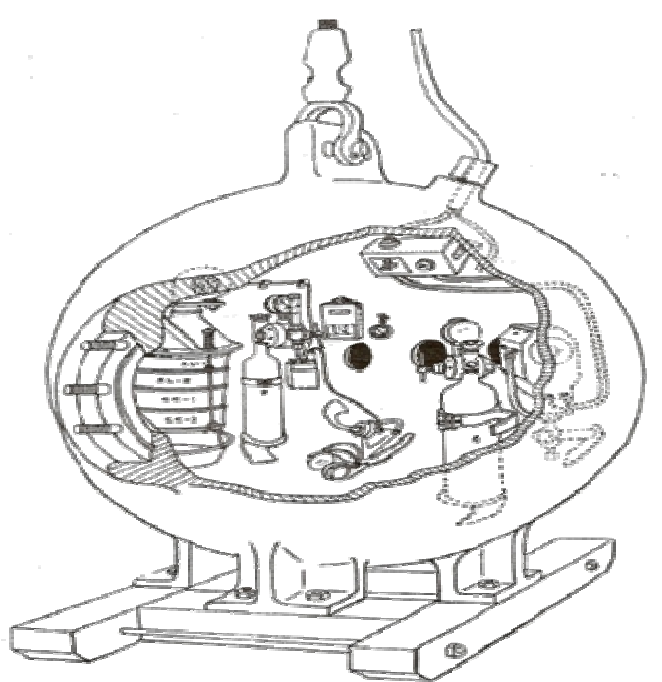

Fig. 1.8. Bathysphere by Prof. W. Beebe (1934) [3]. 
Since it is so difficult for a man unprotected against the effects of the pressure to immerse and work under water, for many years' attempts were made to eliminate this problem, first by ensuring protection against the elevated pressure and next by replacing humans with other technologies.

The earliest concept in the human awareness was related with the development of an unmanned underwater vehicle. The first and the oldest known image of such a device is the construction designed by Roberto Valturi in 1460 (manuscript - printed in 1472) [17, 19]. The drawing of this invention has been preserved until today, however the idea itself was not realised in practice. In the successive three hundred years we see a series of attempts, mistakes, failures and rather insignificant successes.

In 1715 Lethbridge designed and constructed a special barrel enabling performance of simple works at small depths, in 1838 the first armoured suit by Taylor appeared and over a dozen years later the one proposed by Philips (Fig. 1.7) [16]. In the meantime, the first military submarine was constructed and in 1775 used in practice in South America [18]. The 1930s brought about the invention, designed and constructed by William Bebbe and Otis Barton of a bathysphere, which Prof. Bebbe, as the first man on Earth, used to descend to the depth exceeding 900 metres (Fig. 1.8) [3].

Fig. 1.9. Bathyscaph by Prof. A. Piccard (1948) [20]

Professor August Piccard saw the flaws of the bathysphere, for instance, the problems with maintaining a stable position in deep immersion resulting from the rocking movements and trimming of the surface ship, which transferred down the rope used to immerse the bathysphere to the working depth, prompting Piccard to propose a different solution, i.e. a bathyscaphe (Fig. 1.9) [20].

With the use of the third bathyscaphe version Prof. Piccard's son, Jacques, together with lieutenant Donald Walsh of the US Navy on 23 January 1960 were the first men to reach the bottom of the Mariana Trench $[14,21]$. The second bathyscaphe to immense to such a depth was Deep Challenger in 2012 with an American film director, J. Cameron, on board.

\section{Conclusions}

If we look this way on the development of underwater technologies, we may reject the assumption made at the beginning of this article on the poor success in this area. Over multiple years of progress, it was possible to design and construct techniques and technologies enabling humans to reach the bottom of the World's Oceans. However only these techniques that may be defined by the common name of insulation technologies, separating the man from an immediate contact with the aquatic environment, have enabled a really deep immersion.

In the analysis of the development of technologies enabling the conquest of depths one may see a branched, i.e. bifurcated model of this expansion (Fig. 2.1). Generally, it confirms the thesis that the process of development of these technologies has the potential of functioning in two independent currents. The first involves diving technologies applying various solutions in devices used for breathing under water. 


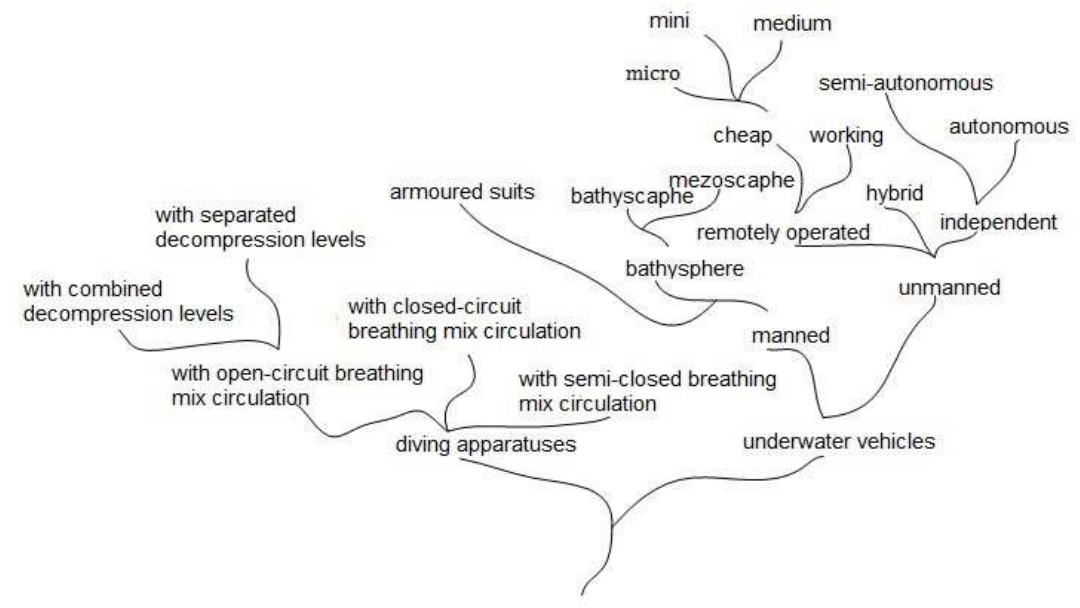

Fig. 2.1. Simplified bifurcated model of development of underwater technologies.

The second current are underwater vehicles. In the case of diving technologies, it seems that on the brink of the 21st century the technological development in this areas has encountered a barrier in the form of human physiology. As it was noted earlier, a man unprotected by any sort of armour was able to reach only $6 \%$ of the depth available on Earth. Thus far there has been no breakthrough in this area and there is nothing to indicate otherwise.

The words spoken by Dr. Phil Nuytten, a constructor of armoured suits, seem to be quite resonant in this aspect: "As human, we like to think of ourselves as a species that's very tough and flexible. But that's absolute horse shit. We're one of the most fragile critters on Earth, designed to live at sea level in a warm environment. We can't go far from those design specifications without a lot of help" [22a]. It is the very reason why the family of underwater vehicles has been developing so vigorously.
At present, unmanned vehicles enable man to perform an exploration at great and extreme depths, however the role of bathyscaphes and mesoscaphes is less significant. Today they rather find a broad application in underwater tourism than in scientific uses. Armoured suits and other diving technologies allow the exploration of the depths by divers in the scope between $300-400$ metres, as for instance the most recent product by Nuytico Research Ltd. from Canada (Fig. 1.11) with the operational depth up to 304 metres.

This means that the prognosis made 15 years ago regarding the virtual presence of man at great depths is still valid. This is mainly due to physiological problems connected with the divers' stay at deep-water working stations, which, on the other hand, constitutes a strong premise to put forward the thesis that deep exploration and work at extremely large depths will be possible, however only with the use of unmanned technologies, presumable with the utilisation of the technique of extended virtual reality.

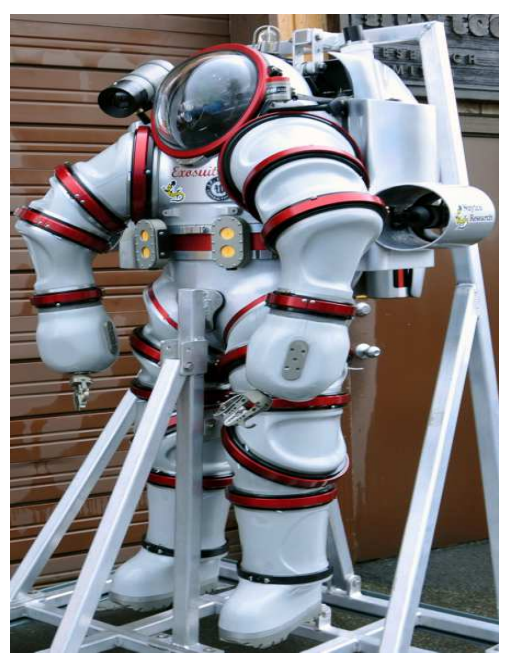

Fig. 1.11. Exsosuit - one-atmosphere diving suite (armoured suite) manufactured by a Canadian company - Nuytico Research Ltd. from North Vancouver [22b]. 


\title{
BIBLIOGRAPHY
}

Olejnik A.: The present state of technology of remotely controlled abyssal vehicles Polish Hyperbaric Research 2009, 3(28), pp. 23 - 46; Olejnik A.: The future of underwater technologies - a diver or a robot? Podwodny Świat 2002, 6 (32) 2002; pp. 22-26;

Beebe W.: 923 metres into the ocean. Trzaska, Evert i Michalski S.A., Warsaw 1935, p. 306;

Olejnik A.: The method of diagnosis surfaces of underwater objects with the use of a visual system, Scientific Journal of Polish Naval Academy, Gdynia 2015, 200A, p. 156, DOI: 10.5604/0860889X;

Collective work: The history of diving. Almapress Warsaw 2003 p. 74;

Halbron S.: 5000 metres under water. MON Warsaw 1959 p. 174

Krzyżak J.: Medycyna dla nurków. KOOPgraf Poznań 2006, p. 664 .

Cousteau J.Y.: The living sea, Publ. Harper \& Row Publishers, USA New York 1963, Biblioteka Kongresu, katalog nr 62-14525, p. 325;

Cousteau J.Y.: World without sun, Harper\&Row Publishers, USA New York 1964 Biblioteka Kongresu no. 65-14690, p. 205;

Kłos R.: Diving apparatuses with breathing mix regeneration, Poznań 2000, p. 448;

11. Olszański R.: Siermontowski P.: ABC of diver health PTMiTH 2002, p. 109,

12. Majchrzycka A.: The diver's thermal comfort in the saturation zone with breathing mixes of diversified thermal properties. Zachodniopomorski Uniwersytet Technologiczny, Szczecin 2012, p. 337;

13. Łaba L.: The prospects of expanding human underwater activity, unpublished material, Institute of Maritime Medicine, Gdańsk 1972 (author's archive);

14. Hussain F.: Living underwater, Prager Publishing Inc., New York 1970, Katalog kongresu 78-129104, p. 125;

15. Gussmann J.: The human conquest of depths. Wydawnictwo Morskie Gdańsk 1984, p. 156;

16. Harris G.L.: Ironsuit - the story of the atmospheric diving suit. Best Publishing Company USA 1994, p. 119;

17. Valturio R.: De re military. Italy 1472

18. Miller D., Jordan J.: Modern submersibles. Espadon Books Ltd., 1993;

19. Olejnik A.: The development of remotely operated abyssal vehicles Polish Hyperbaric Research 2010, 4(33), pp. 7 - -21;

20. Piccard A.: Up to the stratosphere, down into the seas. Iskry Warsaw 1964, p. 238;

21. Woods J.D.: Lythgoe J.N. Underwater science. Oxford University Press 1971, p. 330;

22. Internet sources:

3. Collective work: Future diving suit could lead to a cure for cancer - www.carbonated.tv/technology/diving - 01.2016;

24. Collective work: Exsosuit Specification - www.nuytico.com - 01.2016.

\author{
Adam Olejnik, PhD \\ Polish Naval Academy \\ Department of Underwater Work Technology \\ 81-127 Gdynia \\ ul. Śmidowicza 69 \\ e-mail: a.olejnik@amw.gdynia.pl
}

